\title{
Vorwort
}

\section{zur zweiten Auflage.}

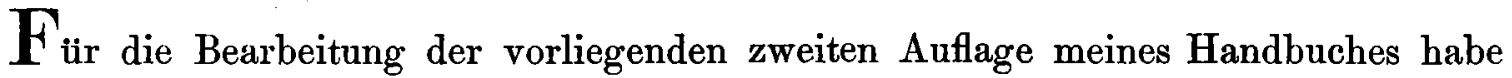
ich mir die doppelte Aufgabe gestellt, einmal alle wesentlichen neueren Fortschritte und Verbesserungen in unserem Fache in die Darstellung aufzunehmen, und sodann die Lüicken und Mängel der ersten Auflage, soweit ich sie bis jetzt erkennen konnte, nach Kräften auszufüllen und zu verbessern.

Der erste Theil meiner Aufgabe war mir der verhältnissmässig leichtere. Seitdem die Geheimnissthuerei aus unserem Fache verschwunden ist, und jede Frage von Wichtigkeit sowohl in den Jahresversammlungen der Fachmänner, als im Journal für Gasbeleuchtung zur offenen und.allseitigen Besprechung gelangt, wird jeder Fortschritt sofort zum Gemeingut, und man braucht nur den Vorgängen unbefangen zu folgen, um ein Bild der stetigen Entwirkelung unseres Faches vor Augen zu behalten. Mit besonderem Dank habe ich übrigens hier namentlich zweier specieller Beiträge zu gedenken, mit denen es mir vergönnt war, die gegenwärtige Auflage des Buches zu schmücken, der „Beschreibung und Zeichnung der neuen Gasanstalt in Frankfurt a.|M. von dem Erbauer und jetzigem Director der Anstalt, Herrn Simon Schiele" und der „Beschreibung und Zeichnung eines in diesem Jahre ausgeführten grossen Telescop-Gasbehälters in Berlin, gleichfalls von dem Erbauer, dem leider viel zu frïh verstorbenen Director, Baumeister Herrn A. Schnuhr."

Dass die erste Auflage meines Buches manche Lücken und Mängel enthält, davon kann Niemand mehr überzeugt sein, als ich. Wohlwollende Freunde haben mich auch in dieser Richtung auf Manches aufmerksam gemacht. Vor allen Dingen habe ich es nöthig gefunden an manchen Stellen weit mehr in's Detail einzugehen, als dies frïher der Fall war, man wird dies zumeist in den Capiteln über die Gasbehälter und über die Leitungsröhren bestätigt finden. Die Beleuchtungsapparate waren in der ersten Auflage ganz uibergangen worden, ich habe sie diesmal in einem besonderen Capitel behandelt auch iiber die bauliche Anlage der Fabriken und die Disposition der Apparate in den Gebäuden habe ich mich ausfiuhrlicher verbreitet.

Der Umfang des Buches ist bedeutend gewachsen, der Text ist von 31 auf 51 Bogen, die Zabl der Tafeln von 42 auf 70 , diejenige der Holzschnitte von 157 auf 310 gestiegen. Die Ausstattung ist die gleiche, wie früher, und es hat die Aner- 
VI

kennung, welche dieselbe allgemein gefunden hat, mich überzeugt, dass ich in dieser Beziehung dem Herrn Verleger nur dankbar sein kann.

Meine Absicht, diesmal dem Buche den schon früher beabsichtigten dritten administrativen Theil hinzuzufügen, habe ich leider wieder nicht zur Ausführung bringen können. Ich behalte es mir vor, diesen Theil in einem besonderen Heft nachzuliefern.

München, im November 1865.

N. H. Schilling. 